\title{
Acetylation Regulates Thioredoxin Reductase Oligomerization and Activity
}

\author{
David E. Wright, Zaid Altaany, ${ }^{1,2}$ Yumin Bi, Zaccary Alperstein, ${ }^{3}$ and Patrick O'Donoghue ${ }^{1,3}$
}

\begin{abstract}
Aims: Thioredoxin reductase 1 (TrxR1) is a cancer target and essential selenoprotein that defends the cell against reactive oxygen species and regulates cellular signaling and redox pathways. Previous cell-based studies correlated TrxR1 acetylation with modulated cellular reduction activity, yet the function of specific acetylation sites on TrxR1 remains unknown.

Innovation: We produced site-specifically acetylated TrxR1 variants that also contain selenocysteine (Sec). We demonstrated efficient high-fidelity protein synthesis with 22 different amino acids by simultaneous UAG codon reassignment to $N_{\varepsilon}$-acetyl-lysine and UGA codon recoding to Sec.

Results: We characterized TrxR1 variants acetylated at physiologically relevant sites and found that single acetylation sites increased TrxR1 activity, enhancing the apparent catalytic rate up to 2.7-fold. The activity increase in acetylated TrxR1 (acTrxR1) is reversible and is reduced following deacetylation with histone deacetylase.

Conclusion: Here we present a novel mechanism through which acetylation increases TrxR1 activity by destabilizing low-activity TrxR1 multimers, increasing the population of active dimeric TrxR1. Antioxid. Redox Signal. 29, 377-388.
\end{abstract}

Keywords: orthogonal translation, post-translational modification, redox, selenoprotein, $\mathrm{tRNA}^{\mathrm{Sec}}$, tRNA ${ }^{\mathrm{Pyl}}$

\section{Introduction}

$\mathbf{H}$ UMAN CELLS NATURALLY defend against reactive oxygen species (ROS) using a network of redox enzymes, including the selenoprotein thioredoxin reductase 1 (TrxR1) (38). Selenoproteins contain the 21 st genetically encoded amino acid, selenocysteine ( $\mathrm{Sec}$ ). In cells, the Sec550 residue in TrxR1 is required for most of its activity (42) in reducing oxidized compounds, for example, ubiquinone (53), and oxidatively damaged cellular proteins via a redox-coupled reaction with thioredoxin (Trx). TrxR1 catalyzes the transfer of electrons from $\beta$-nicotinamide adenine dinucleotide 2 -phosphate (NADPH) to Trx1. The reduced Trx1 in turn resolves oxidized species and reduces cellular proteins. The resulting oxidized Trx1 is then recycled by the TrxR1 enzyme. In addition to ROS defense, the Trx system is involved in regulating gene expression, embryonic development, cell proliferation, and apoptosis (27).

\section{Innovation}

Proteins are normally synthesized in cells with 20 amino acids, but most are post-translationally modified at many sites with unknown consequences to protein function. We used two mutually orthogonal translation systems to incorporate 22 genetically encoded amino acids into a single protein with efficiency and fidelity identical to normal protein synthesis. In doing so, we produced a purified human enzyme in a native and more fully active form, and importantly, we uncovered acetylation as a novel mechanism of enhancing thioredoxin reductase 1 activity that has broad implications for cellular signaling and disease pathways related to deregulation of the cellular redox status.

Departments of ${ }^{1}$ Biochemistry and ${ }^{3}$ Chemistry, The University of Western Ontario, London, Canada.

${ }^{2}$ Department of Basic Sciences, Faculty of Medicine, Yarmouk University, Irbid, Jordan.

(C) David E. Wright et al. 2018; Published by Mary Ann Liebert, Inc. This Open Access article is distributed under the terms of the Creative Commons License (http://creativecommons.org/licenses/by/4.0), which permits unrestricted use, distribution, and reproduction in any medium, provided the original work is properly cited. 
Overactive TrxR1 is associated with chemotherapeutic resistance, and TrxR1 activity is co-opted by cancer cells to defend against ROS generated by therapeutic compounds (35). TrxR1 activity levels are diagnostic for early detection of lung (39) and breast cancers (8), and TrxR1 has emerged as a target to combat drug-resistant lung cancers, for example, ethaselen (49). In mouse models of age-related macular degeneration and glaucoma, overexpression of amyloid $\beta$ was associated with increased TrxR1 activity despite unperturbed TrxR1 protein abundance, implicating post-translational modifications in regulating TrxR1 activity (25). Differential total TrxR activity and changes in TrxR1 acetylation status were also associated with a cardiomyopathy phenotype in transgenic mice (2) and in retinal tissue from diabetic rat models and human postmortem patient samples (26). TrxR1 is acetylated on at least three specific sites on the protein surface that have been experimentally identified in humans and mice $(7,21,50)$.

Due to the emerging association of TrxR1 acetylation, cellular redox status, and disease, we investigated how acetylation signaling modulates TrxR1 activity. Because the acetyl transferase(s) that acetylate TrxR1 in the cell are unknown, it was not possible to produce site-specifically acetylated TrxR1 variants using an upstream enzyme or from expression in human cell culture. We overcame this barrier by using two genetic code expansion systems (Fig. 1) that enabled cotranslational incorporation of both Sec and $N_{\varepsilon}$-acetyllysine $(\mathrm{acK})$ residues at specific sites, resulting in sitespecifically acetylated and differentially active human TrxR1 selenoprotein variants.

\section{Results}

To biochemically characterize the impact of sitespecific acetylation on the reduction activity of TrxR1, we produced TrxR1 variants in Escherichia coli with 22 different genetically encoded amino acids, including the noncanonical amino acids (ncAAs) acK and Sec (Fig. 1). The data show, for the first time, that we produced protein with 22 different amino acids with equal efficiency and fidelity to protein production with the 20 standard amino acids (Table 1).
A
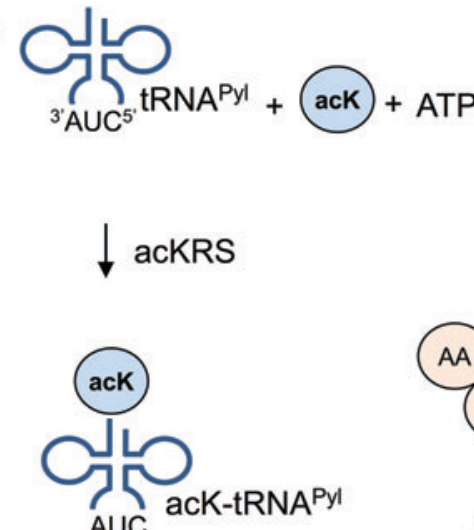

AUC
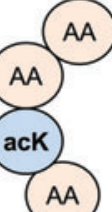
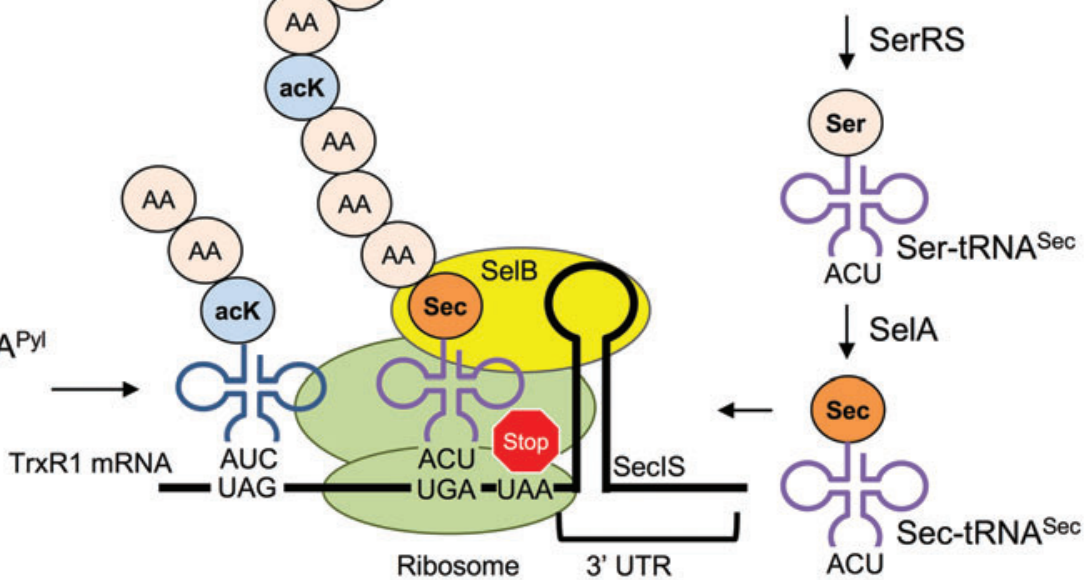

B

6xHis-TrxR1 (human)
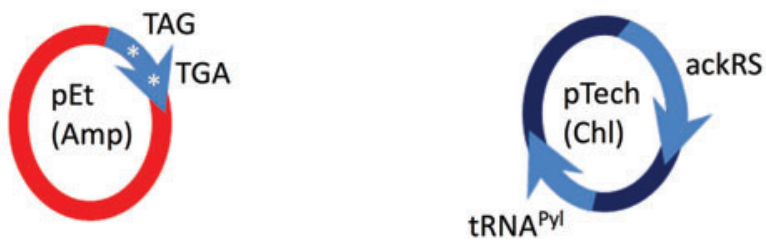

FIG. 1. Schematic for genetically encoding 22 amino acids. (A) Genetically encoding acK and Sec: acKRS ligates acK to tRNA $^{\text {Pyl }}$, which reassigns all UAG stop codons to acK. This allows insertion of acK at a specific UAG codon in TrxR1. For Sec insertion, tRNA ${ }^{\mathrm{Sec}}$ is aminoacylated with serine (Ser) by seryl-tRNA synthetase (SerRS), followed by conversion of Ser-tRNA to Sec-tRNA by selenocysteine synthase (SelA). The elongation factor SelB binds Sec-tRNA ${ }^{\text {Sec }}$ as well as the SecIS, which we designed into the $3^{\prime}$ UTR of the TrxR1 mRNA. The SecIS localizes Sec-tRNA ${ }^{\text {Sec }}$ at the UGA codon, allowing for Sec insertion at a single UGA stop codon. (B) The two-plasmid system required for production of acetylated TrxR1: the pTech vector expresses AcKRS and tRNA ${ }^{\text {Pyl }}$, required for reassignment of UAG codons to acK. The pET vector expresses TrxR1 with a TAG at the desired acetylation sites $(141,200$, or 307), as well as SecIS in the 3' UTR (see the "Materials and Methods" section). In this system, UAG genetically encodes acK, while SecIS following downstream of the UGA codon is required for Sec insertion. The Sec synthesis and insertion system is endogenous to Escherichia coli, encoded in the E. coli genome (SelA, SelB, SelC, SelD, SerRS). 3' UTR, 3' untranslated region; acK, $N_{\varepsilon}$-acetyl-lysine; acKRS, mutant pyrrolysyl-tRNA synthetase ( $N_{\varepsilon}$-acetyl-lysine-tRNA synthetase); Sec, selenocysteine; SecIS, selenocysteine insertion sequence; TrxR1, thioredoxin reductase 1. To see this illustration in color, the reader is referred to the web version of this article at www.liebertpub.com/ars 
Table 1. Thioredoxin Reductase 1 and acetylated Thioredoxin Reductase 1 Protein Yields and Activity

\begin{tabular}{|c|c|c|c|c|c|c|c|c|}
\hline \multirow[b]{2}{*}{$\operatorname{Tr} x R 1$ variant } & \multirow[b]{2}{*}{$\begin{array}{l}\triangle R F 1, \\
\text { protein } \\
\text { yield, } \\
(\mathrm{mg} / \mathrm{L})\end{array}$} & \multirow[b]{2}{*}{$\begin{array}{l}\text { BL21, } \\
\text { protein } \\
\text { yield, } \\
(\mathrm{mg} / \mathrm{L})\end{array}$} & \multicolumn{2}{|c|}{ DTNB assay } & \multicolumn{2}{|c|}{$\begin{array}{c}\text { 9,10-Phenanthrequinone } \\
\text { assay }\end{array}$} & \multicolumn{2}{|c|}{$\begin{array}{l}\text { Insulin linked } \\
\text { Trxl assay }\end{array}$} \\
\hline & & & $\begin{array}{c}\text { Initial } \\
\text { velocity } \\
(\text { pmol TNB/s) }\end{array}$ & $\begin{array}{l}\text { Relative } \\
\text { activity } \\
(x \text {-fold })\end{array}$ & $\begin{array}{c}\text { Initial velocity } \\
\text { (pmol NADPH } \\
\text { consumed/s) }\end{array}$ & $\begin{array}{l}\text { Relative } \\
\text { activity } \\
(x \text {-fold })\end{array}$ & $\begin{array}{c}\text { Initial velocity } \\
\text { (pmol NADPH } \\
\text { consumed/s) }\end{array}$ & $\begin{array}{l}\text { Relative } \\
\text { activity } \\
(x \text {-fold })\end{array}$ \\
\hline WT TrxR1 & 0.4 & 2.4 & $0.24 \pm 0.01$ & 1.0 & $1.23 \pm 0.03$ & 1.0 & $0.22 \pm 0.02$ & 1.0 \\
\hline $\operatorname{acTrxR} 1^{\mathrm{K} 141}$ & 0.4 & 0.7 & $0.42 \pm 0.03$ & 1.8 & $1.53 \pm 0.05$ & 1.2 & $0.41 \pm 0.01$ & 1.8 \\
\hline acTrxR $1^{\mathrm{K} 200}$ & 0.5 & 2.6 & $0.49 \pm 0.01$ & 2.1 & $1.78 \pm 0.14$ & 1.4 & $0.42 \pm 0.01$ & 1.9 \\
\hline $\operatorname{acTrxR} 1^{\mathrm{K} 307}$ & 0.6 & 0.7 & $0.64 \pm 0.07$ & 2.7 & $1.61 \pm 0.08$ & 1.3 & $0.43 \pm 0.01$ & 2.0 \\
\hline inactive $\operatorname{TrxR} 1^{\mathrm{U} 550 \mathrm{Y}}$ & n.d. & 2.1 & n.d. & - & - & - & n.d. & - \\
\hline
\end{tabular}

Protein yield was measured using the Bradford assay and noted above in milligrams of TrxR1 produced per liter of Escherichia coli culture from the indicated strain.

acTrxR1, acetylated thioredoxin reductase 1; DTNB, 5, $5^{\prime}$-dithiobis-(2-nitrobenzoic acid); NADPH, $\beta$-nicotinamide adenine dinucleotide 2'-phosphate; n.d., not determined; RF1, release factor 1; Trx1, thioredoxin 1; TrxR1, thioredoxin reductase 1; WT, wild type

\section{E. coli host strain alters expression of TrxR1 with 22 amino acids}

We combined two genetic code expansion systems in E. coli to produce site-specifically acetylated TrxR 1 variants (Fig. 1). We reassigned UAG codons from stop to acK using a mutant UAG-decoding pyrrolysyl-tRNA synthetase (acKRS) and tRNA ${ }^{\mathrm{Pyl}}$ pair $(12,16,45)$, and we simultaneously recoded a specified UGA codon from stop to Sec with the native E. coli Sec insertion system (Fig. 1). We produced and purified wild-type (WT) TrxR1 with Sec at position 550, and three site-specifically acetylated variants (acTrxR1 ${ }^{\mathrm{K} 141}$, acTrxR1 ${ }^{\mathrm{K} 200}$,

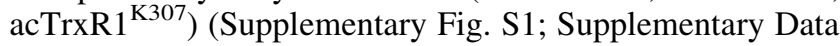
are available online at www.liebertpub.com/ars). Production of these protein variants required the two-plasmid system depicted in Figure 1 and described in the Materials and Methods section.

We tested the expression of TrxR1 and acetylated TrxR1 (acTrxR1) variants in E. coli BL21 DE3 and in an E. coli strain (C321. $\Delta$ A.exp) that lacks release factor 1 (RF1) and all genome encoded UAG codons (E. coli $\triangle \mathrm{RF} 1)$ (24). RF1 terminates translation at UAG. E. coli $\triangle \mathrm{RF} 1$ should allow for more efficient reassignment of $U A G$ to acK, since there is less competition between acK-tRNA ${ }^{\text {Pyl }}$ and RF1 for binding UAG. With the acK incorporation system (Fig. 1A), we demonstrated efficient UAG read-through per cell using a GFP reporter in E. coli $\triangle \mathrm{RF} 1$ (Supplementary Fig. S2). Unfortunately, and concordant with our previous work (14), the E. coli $\triangle \mathrm{RF} 1$ strain produces significantly less recombinant TrxR1 (Table 1) due to phenotypic defects resulting in slow growth and markedly reduced cell densities $(14,24)$. Potential benefits from RF1 deletion are subsumed by the more efficient protein producing stain BL21, which produces more overall UAG translation per 1 E. coli culture.

Fascinatingly, BL21 protein production efficiency was indistinguishable $(2-2.6 \mathrm{mg} / \mathrm{L}$ culture) for variants of TrxR1 containing 20 (Sec550Tyr), 21 (WT), or $22\left(\operatorname{acTrxR} 1^{\mathrm{K} 200}\right)$ genetically encoded amino acids (Table 1). In BL21, we observed yields for protein containing 22 genetically encoded amino acids of up to $2.6 \mathrm{mg} / \mathrm{L}$ culture, whereas the $E$. coli $\triangle \mathrm{RF} 1$ showed a maximal protein production of $0.6 \mathrm{mg} / \mathrm{L}$ culture. BL21 produced 1.2- to 5-fold more TrxR1 or acTrxR1 compared to E. coli $\triangle \mathrm{RF} 1$ (Table 1).

\section{Physical characterization of TrxR1 variants}

We confirmed insertion of Sec and acK into the same protein variants by multiple independent mass spectroscopic methods. Independent mass spectrometry (MS) techniques confirmed quantitative incorporation of Sec and/or acK in each TrxR1 variant (Fig. 2 and Supplementary Fig. S3-S6). Matrix-assisted laser desorption/ionization mass spectrometry (MALDI-MS) analysis of the acTrxR1 variants confirmed sitespecific acetylation at each of the anticipated sites (Supplementary Fig. S3), and verified Sec incorporation in WT TrxR1 (Supplementary Fig. S4). In addition, we found no evidence of deacetylation in the MALDI data (Supplementary Fig. S3). To verify Sec incorporation and to determine the number of active molecules in each sample, we quantified the amount of selenium (Se) in the TrxR1 variants. Because Sec is required for
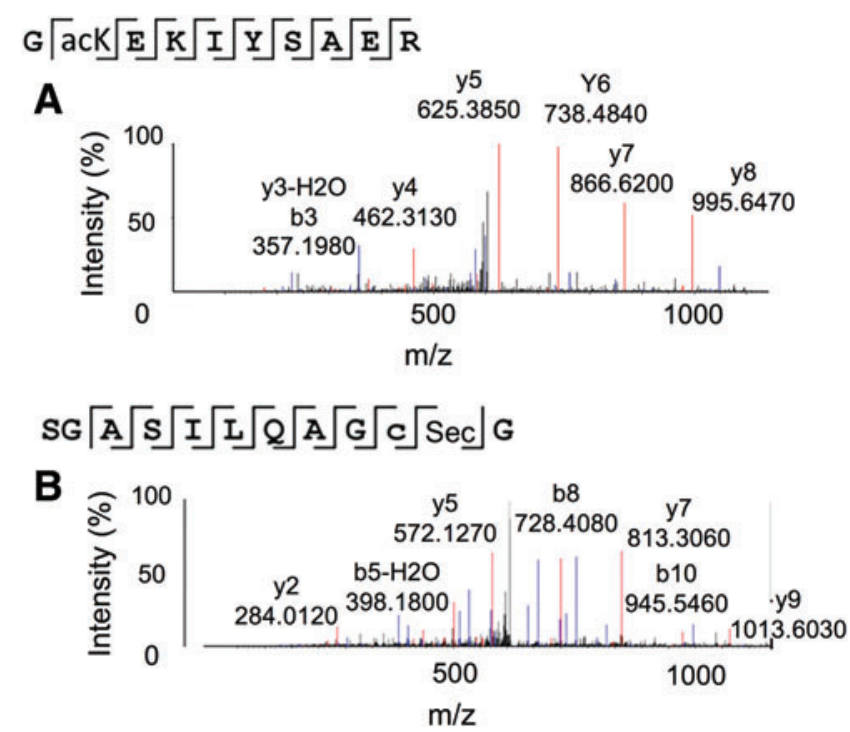

FIG. 2. Physical identification of acK and Sec in acTrxR1 $^{\text {K200 }}$. Mass spectrometry data for other TrxR1 variants are shown in Supplementary Figures S3-S6. Liquid chromatography tandem mass spectrometry of polypeptides from trypsin digested acTrxR $1^{\mathrm{K} 200}$, demonstrating (A) acK and (B) Sec incorporation at the desired locations. acTrxR1, acetylated TrxR1. To see this illustration in color, the reader is referred to the web version of this article at www.liebertpub.com/ars 
TrxR1 activity, the amount of Se covalently bound to the protein indicates the amount of active TrxR1. Inductively coupled plasma mass spectrometry (ICP-MS) verified quantitative insertion of Sec in the TrxR1 variants (Supplementary Table S1). Liquid chromatography tandem mass spectrometry (LC-MS/MS) revealed acK incorporation (Fig. 2 and Supplementary Fig. S6) and Sec incorporation (Fig. 2 and Supplementary Fig. S5) at the programmed locations for acTrxR1 ${ }^{\mathrm{K} 141}$ (Supplementary Figs. S5B and S6A), acTrxR1 ${ }^{\mathrm{K} 200}$ (Fig. 2), and acTrxR1 $^{\mathrm{K} 307}$ (Supplementary Figs. S5C and S6B), as well as Sec incorporation for WT TrxR1 (Supplementary Fig. S5A). In each MS experiment, we were unable to detect deacetylation or mistranslation at the UAG- or UGA-encoded loci.

\section{Reversible activation of TrxR1}

The enzymatic activity of TrxR1 was assessed on three substrates: 5,5'-dithiobis-(2-nitrobenzoic acid) (DTNB), 9, 10phenanthrequinone, and Trx1 in an insulin coupled assay (28). DTNB is a long-established artificial substrate for TrxR1 (28), while 9,10-phenanthrequinone and the Trx1 insulin linked assays are dependent on the presence of Sec in TrxR1 (4). DTNB and the quinone assays measure TrxR1 reduction ac-
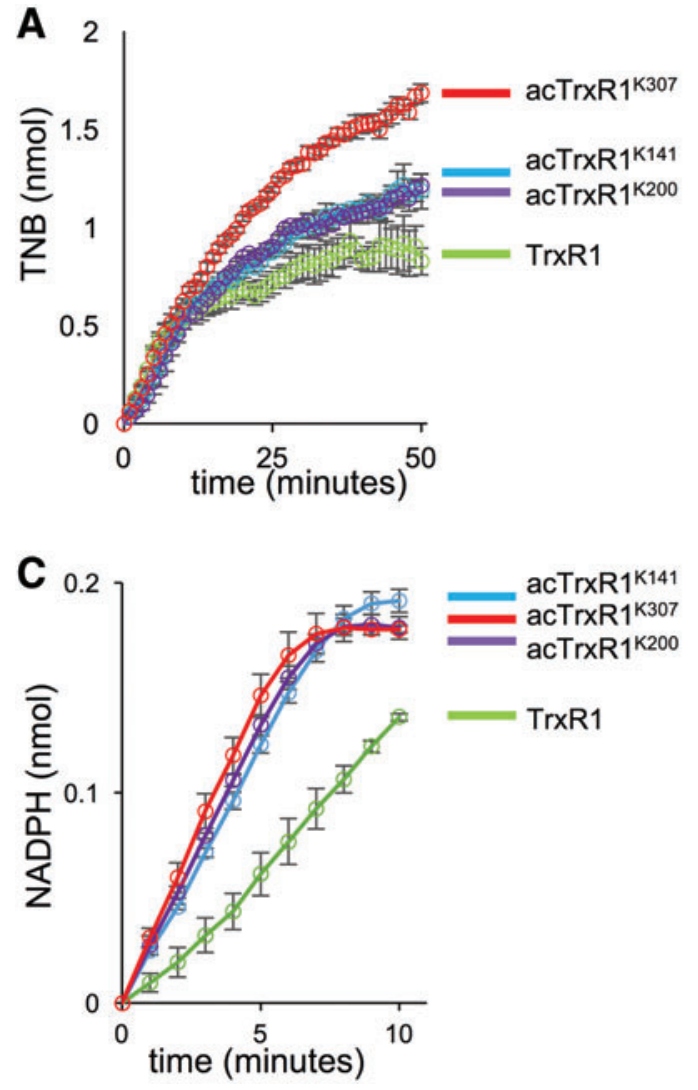

tivity directly, while the insulin linked assay also includes Trx1 and recapitulates a model TrxR1 redox pathway in vitro.

In comparison with WT TrxR1, each acTrxR1 variant had a statistically significantly higher activity on all substrates tested (Fig. 3). acTrxR1 ${ }^{\mathrm{K} 307}$ was most active in DTNB assays, while acTrxR $1^{\mathrm{K} 200}$ showed the highest activity with the quinone substrate (Fig. 3D), suggesting that acetylation may affect TrxR1 substrate preference. Although TrxR1 lacking the Sec residue is still active with DTNB at a low level, 9,10phenanthrequinone reduction by TrxR 1 is more Sec dependent (54). We observed that a disabled TrxR1 variant (Sec550Tyr) shows basal activity in the quinone assay (Fig. 3B). In agreement with the MS data, the activity data demonstrate that WT and acTrxR1s all contain Sec (Fig. 3B). Cotranslational incorporation of acK had no apparent effect on the proper folding of the enzyme (Fig. 4).

We performed a series of TrxR1 activity assays with or without preincubation with histone deacetylase 3 (HDAC3). HDAC3 decreased the activity of the $\operatorname{acTrxR} 1^{\mathrm{K} 141}$ and acTrxR1 ${ }^{\text {K307 }}$ variants to WT TrxR1 levels, but HDAC3 did not alter WT TrxR1 activity (Fig. 5). HDAC3 caused a slight decrease in the activity of acTrxR $1^{\mathrm{K} 200}$, but this decrease was at the borderline of statistical significance (Fig. 5). Although
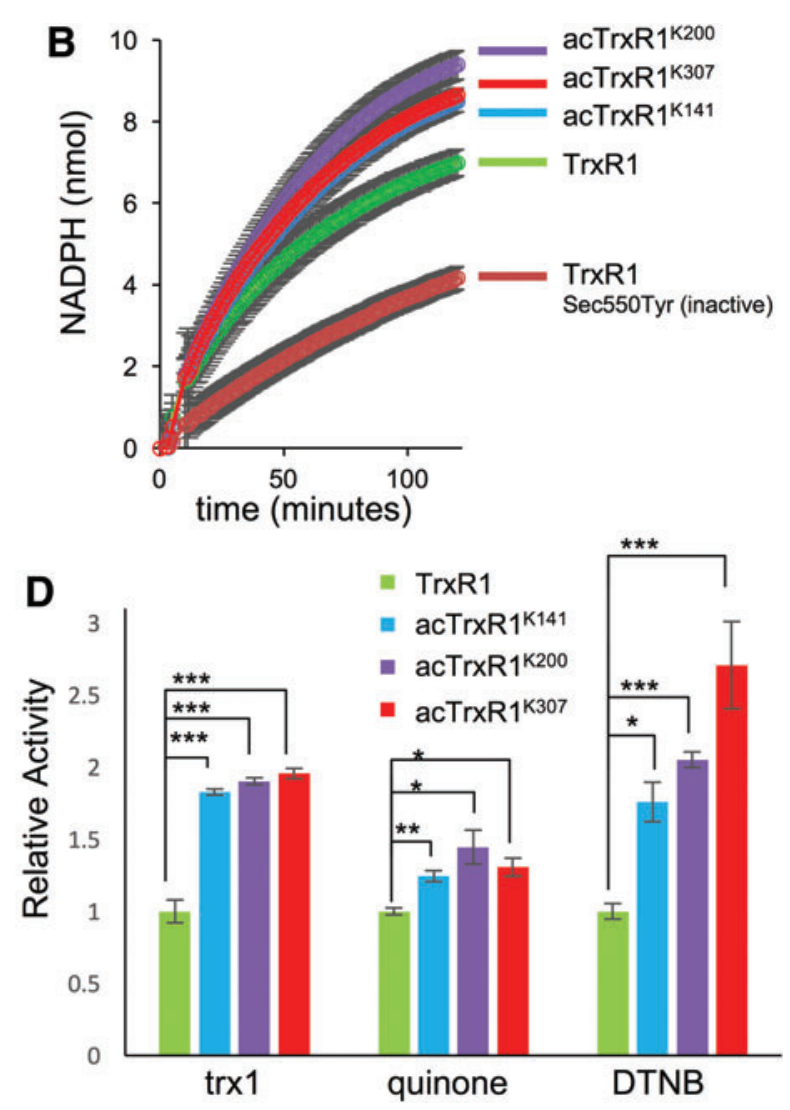

FIG. 3. Activity of TrxR1 and acTrxR1 variants. In vitro activity assay of WT and acTrxR1 variants using a colorimetric (A) DTNB reduction assay measuring TNB production $(412 \mathrm{~nm})$ with $50 \mathrm{n} M$ of each TrxR1 variant, (B) a 9,10-phenanthrenequinone reduction assay with $100 \mathrm{n} M$ of each TrxR1 variant monitoring NADPH depletion (340 nm), or (C) a Trx1-insulin linked assay using $200 \mathrm{n} M$ of TrxR1 and $6 \mu M$ Trx 1 monitoring NADPH depletion (340 nm). In the Trx1 insulin linked assay, TrxR1 reduces Trx1, which then reduces insulin before being reduced again by TrxR1. (D) The relative activity of the TrxR1 variants for each substrate, where the velocity (TNB/s or NADPH consumed/s) of WT TrxR1 is set to 1 . These velocities were calculated from the data shown $(\mathbf{A}-\mathbf{C}) .(* p<0.05, * * p<0.01, * * * p<0.005)$. Error bars represent one standard deviation based on triplicate measurements. A no enzyme control has been subtracted from all enzyme assays shown. DTNB, 5,5'-dithiobis-(2-nitrobenzoic acid); $\mathrm{NADPH}, \beta$-nicotinamide adenine dinucleotide 2 '-phosphate; Trx 1, thioredoxin 1; WT, wild type. To see this illustration in color, the reader is referred to the web version of this article at www.liebertpub.com/ars 
FIG. 4. CD spectra of TrxR1 variants. $C D$ spectra demonstrates properly folded WT TrxR1 (A) and acTrxR1 (B-D) variants, indicating no changes in protein folding caused by cotranslational incorporation of acK. Data are collected in units of mean residue ellipticity (in $\operatorname{deg} \mathrm{cm}^{2} /$ dmol). CD, circular dichroism. To see this illustration in color, the reader is referred to the web version of this article at www.liebertpub .com/ars
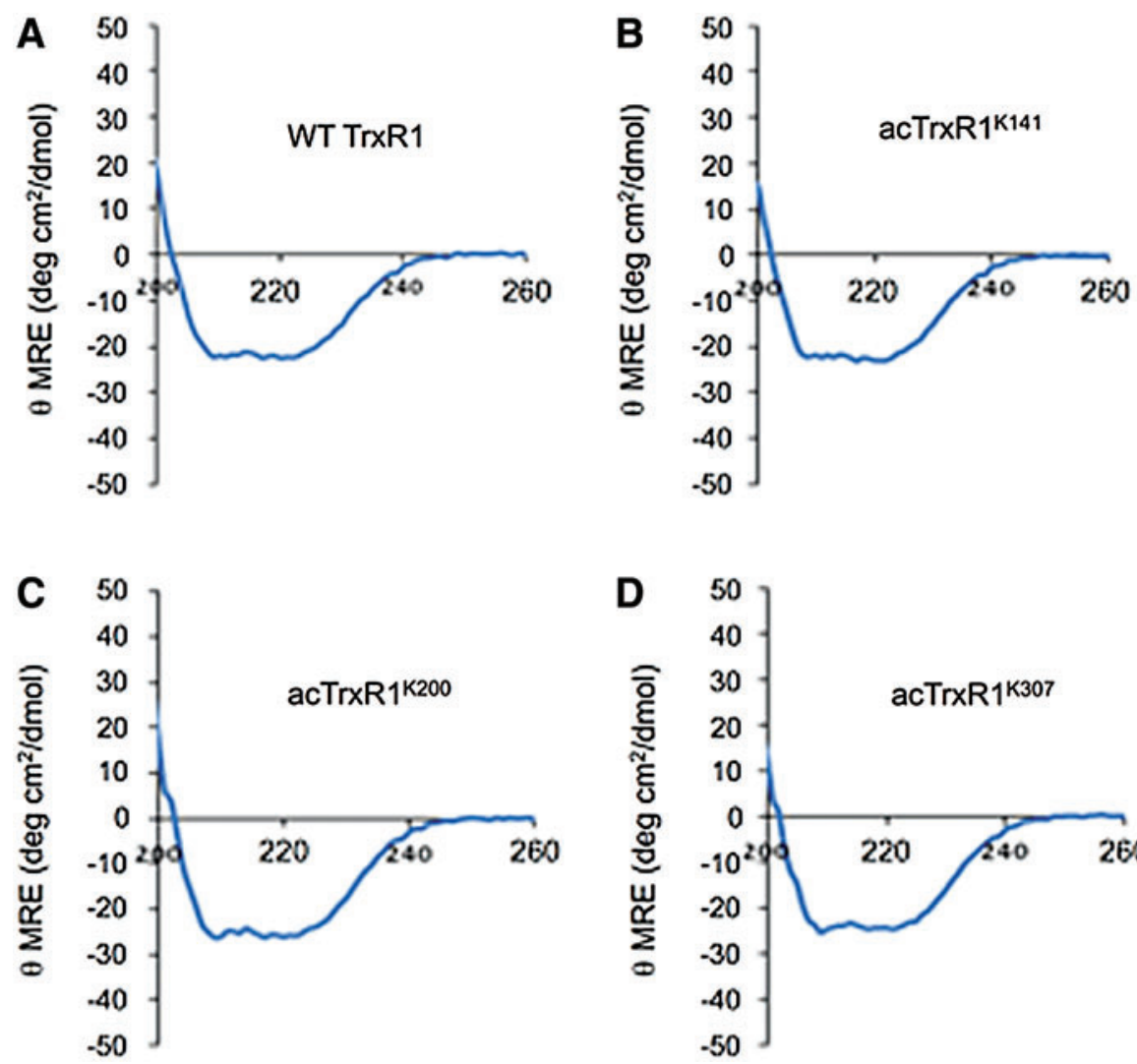

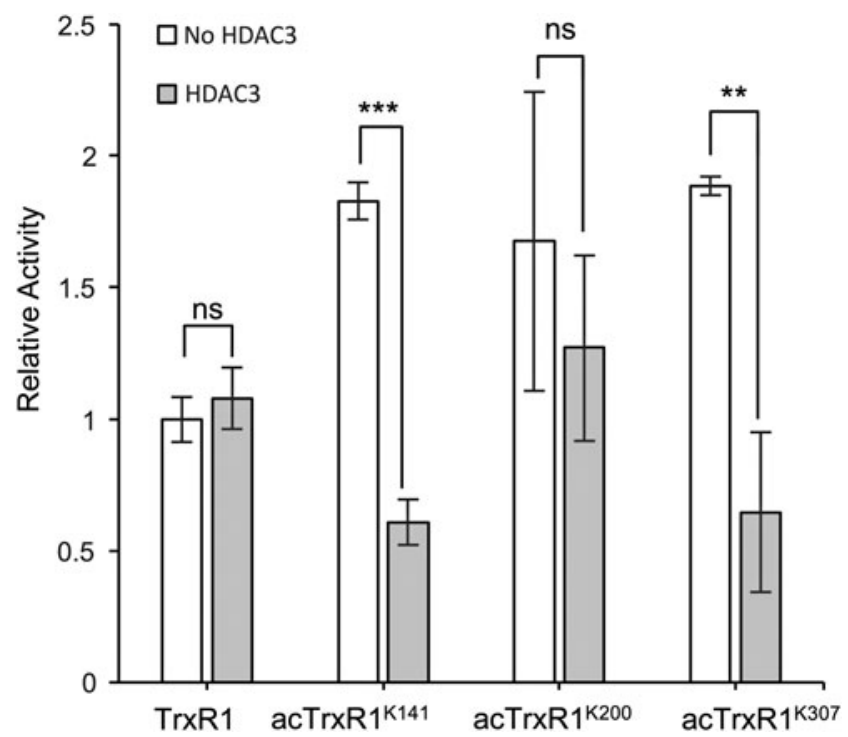

FIG. 5. Effect of HDAC on TrxR1 variants. The in vitro activity of TrxR1 variants, using $3.75 \mathrm{n} M$ TrxR1 incubated with or without HDAC3, was measured by monitoring TNB production $(412 \mathrm{~nm})$. The relative activity for each variant incubated with (filled bars) or without (open bars) HDAC3, where the initial velocity of unacetylated TrxR1 incubated without HDAC3 is set to 1 . Error bars represent one standard deviation $(* * p<0.01, * * * p<0.005$, ns, not significant). All error bars represent one standard deviation of triplicate measurements. HDAC3, histone deacetylase 3. not evident in the MS data, these data suggest that $\operatorname{acTrxR} 1^{\mathrm{K} 200}$ may be either partially deacetylated or perhaps less accessible to HDAC3. The data show conclusively that acetylation is a reversible mechanism to enhance TrxR1 activity at sites K141 and K307. A single acetylation at K307 leads to a 2.7-fold increased TrxR1 activity (Fig. 3; Table 1).

\section{Acetylation alters TrxR1 quaternary structure}

In solution, catalytically active dimeric TrxR 1 exists in equilibrium with inactive tetramers and higher order multimers (54). A structure of the TrxR1 tetramer (54) revealed that all three lysine acetylation sites are localized at the dimer-dimer interface [Fig. 6, PBD 4KPR (54) and 3EAN (6)]. In fact, acetylation will interfere with charge balanced hydrogen bond networks of glutamate or aspartate and lysine residues lining the tetramer interface (Fig. 6B, C). Acetylation at K141 disrupts a symmetrical hydrogen bond network at the core of the dimer-dimer interface between K141 and E143 (Fig. 6B). Additionally, acetylation at K200 or K307 likely perturbs a distinct and extensive hydrogen bond and salt bridge network between glutamate and lysine residues at the edges of the tetramer (Fig. 6C). In fact, a recent report identified acetylation at K147, which is also located in the TrxR1 dimer-dimer interface, in human lung cancer cells treated with the HDAC inhibitor suberoylanilide hydroxamic acid (52).

Catalytically active TrxR1 dimers were separated from low-activity monomers and tetramers for each TrxR1 variant by native size exclusion chromatography (Fig. 7). DTNB activity assays demonstrated the TrxR1 variants were successfully separated. In agreement with a previous study on 


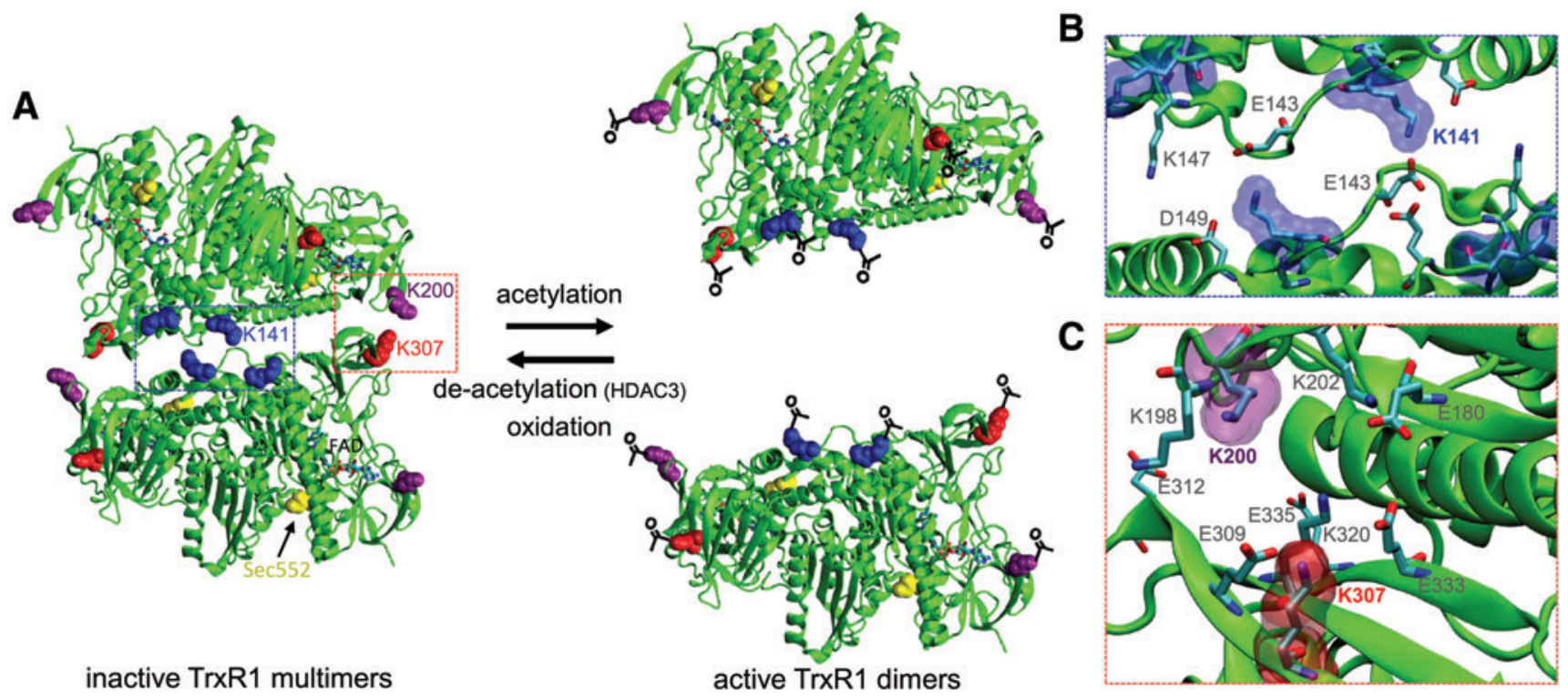

FIG. 6. Mechanistic basis for acetylation-dependent enhanced TrxR1 activity. (A) Acetylation of K141 (blue), K200 ( purple), or K307 (red) on the surface of TrxR1 dimers interferes with salt bridges and hydrogen bonds (B, C) in the TrxR1 tetramer interface. Close-up view of the interactions at the tetramer interface with (B) K141, (C) K200, and K307 [PBD: $4 \mathrm{KPR}$ (39) and 3EAN (5)]. To see this illustration in color, the reader is referred to the web version of this article at www.liebertpub.com/ars

the role of Trp114 oxidation in driving TrxR1 tetramer formation (54), the highest activity fractions contained dimers, while fractions containing monomers or tetramers showed markedly reduced activity (Fig. 7B). The oxidation of Trp114 also leads to a covalent linkage between two TrxR1 monomers (54), forming a nonproductive and covalently linked dimer. As evident in the Western blot (Fig. 7), we observed fewer covalently linked inactive TrxR1 subunits in the acetylated TrxR1 variants compared with WT TrxR1 (Fig. 7A, C). Western blot analysis of the fractions confirms that a larger fraction of the acTrxR1s eluted as catalytically active dimers compared with WT TrxR1 (Fig. 7C, Supplementary Table S2). The data further suggest that the acTrxR1 and WT TrxR1 dimer fractions have similar activity (Fig. 7B), and the increased activity observed in the bulk measurements (Fig. 3) is attributable to the increased population of active dimers in acTrxR1, decreased tetramer formation in acTrxR1 (Fig. 7C, Supplementary Table S2), and decreased amounts of nonproductive covalently linked dimers in acTrxR1 compared with WT TrxR1 (Fig. 7C). The data suggest a novel mechanism (Fig. 6), through which acetylation reduces tetramer/multimer formation and promotes the formation of active TrxR1 dimers.

\section{Discussion}

\section{Acetylation controls TrxR1 structure and activity}

Lysine acetylation is found in all domains of life (10, 40, 51) with 36,000 acetylation sites identified in human, rat, and mouse cells $(7,21)$. The human acetylome is enriched in proteins that form macromolecular complexes (7). Acetylation of p53 blocks its oligomerization leading to nuclear export (23). Histone acetylation prevents oligomerization, inhibiting chromatin condensation and increasing transcriptional activity (43). Although not previously known for thioredoxin reductase, our data indicate that a similar mechanism may allow cells to control the pool of active molecules by suppressing TrxR1 oligomerization (Fig. 6). Acetylation of TrxR1 may also counteract oxidative inactivation of the enzyme. Oxidative modification at Trp114 (54), centrally located in the dimer-dimer interface, was shown to reduce TrxR 1 activity by promoting TrxR1 oligomerization, which represents a counteracting mechanism relative to acetylation (Fig. 6) (54). Indeed, the data suggest that TrxR1 acetylation may enable reactivation of oxidatively damaged TrxR1 multimers (Fig. 7). In addition, acetylation of the TrxR1 substrate, Trx1, increases the activity of Trx 1 through a currently unknown mechanism (46). Acetylation of another protein target of the Trx system, peroxiredoxin (Prx), prevents superoxidation of the Prx protein, increases its reduction activity, and prevents the formation of high-molecular-weight complexes with Prx and other proteins (33).

\section{Relevance to human disease}

The ability to regulate TrxR1 activity via acetylation will have relevance to major human diseases, including neurodegeneration, cancer, diabetes, and aging (37), which are characterized or complicated by elevated ROS. Decreased TrxR1 activity without changes in TrxR1 levels has been implicated in age-related macular degeneration and glaucoma resulting from overexpression of amyloid $\beta$ peptides (25), indicating that post-translational modifications control TrxR1 activity. Differential acetylation of TrxR1 was also documented in human cells (7) and in a mouse model of cardiomyopathy (2). Initial findings have implicated TrxR1 regulation by deacetylation in diabetes. In hyperglycemic rats, physical association with HDAC6 and decreased acetylation of TrxR1 correlated with reduced TrxR1 activity (26) in agreement with our data. 
A
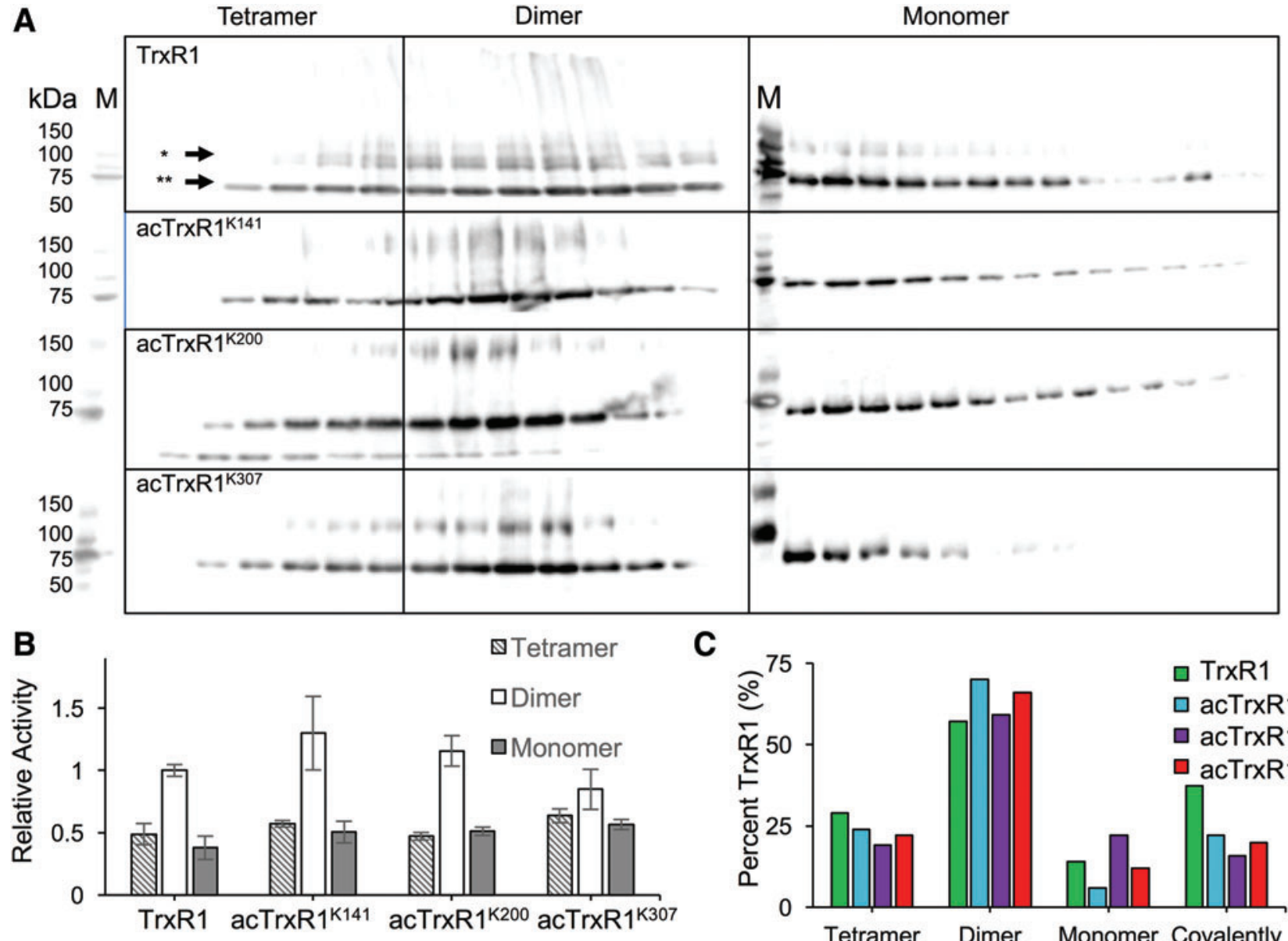

C

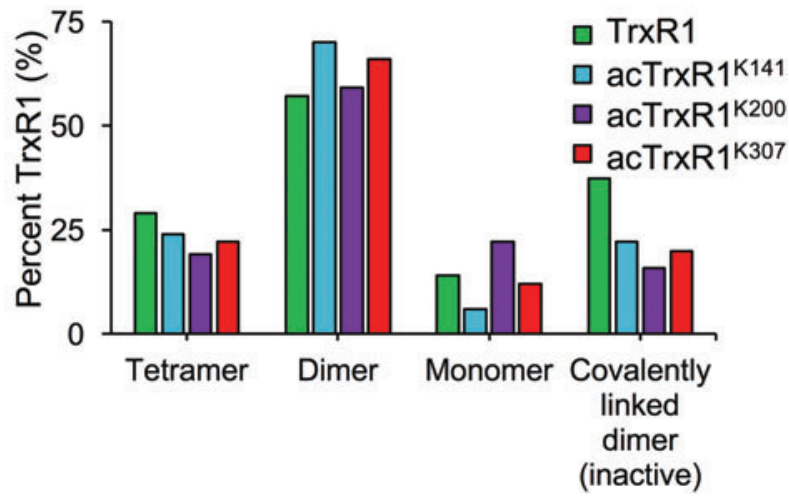

FIG. 7. Characterization of WT TrxR1 and acTrxR1 oligomerization. (A) Different oligomeric states of the TrxR1 variants were separated in native conditions on a size exclusion column. His 6 -TrxR1 present in the fractions was visualized by Western blotting (anti-His). Arrows indicate TrxR1 subunits (**) or covalently linked and nonproductive TrxR1 dimers (*) formed during tetramerization. $\mathrm{M}$ indicates a molecular weight marker. (B) DTNB activity assays (100 $M$ TrxR1) demonstrated that high-activity dimers were successfully separated from low-activity tetramers and monomers. Relative activity is based on initial velocity $(\mathrm{TNB} / \mathrm{s})$, where the unacetylated dimer is set to 1 . Error bars represent one standard deviation based on triplicate experiments. (C) The percent of TrxR1 existing as dimers, tetramers, monomers, or covalently linked inactive dimers was plotted for each TrxR1 variant. Percentages are calculated based on densitometry of the Western blot (A). To see this illustration in color, the reader is referred to the web version of this article at www.liebertpub.com/ars

In several forms of cancer, TrxR1 expression and activity are used as diagnostic markers for early detection $(8,39)$. As our data indicate, acetylation increases TrxR1 activity, and future work will include investigating TrxR1 acetylation as a potential diagnostic marker. Cells can overcome ROS generating cancer therapies and turn off apoptotic pathways by overexpressing TrxR1 (36). In addition, inhibiting the Trx system has been shown to increase the effectiveness of radiation therapy in treating some forms of breast cancer (34). Oxidative stress is known to reduce TrxR1 activity by inducing tetramer formation (54). Previous data suggest that the cell responds to oxidative stress by acetylating TrxR1, perhaps enabling resistance to therapies that generate ROS (2). We hypothesize that, in the cell, acetylation of TrxR1 reduces the oxidative stress-induced tetramerization of TrxR1 (54) generated by radiation and chemotherapies (15).
Together, these studies suggest that identifying and inhibiting TrxR acetylases may serve as another route to increase the effectiveness of cancer therapies.

\section{Impacts of enhanced TrxR activity on cellular signaling}

The Trx system is directly involved in cellular signaling linked to cell proliferation and viability (27). A classic example includes the role of reduced Trx1 in inhibiting apoptosis. Reduced Trx1 inhibits apoptosis signal-regulating kinase (apoptosis signal-regulating kinase 1 [ASK1]) by directly binding to the kinase (36). Inhibition of TrxR with 1chloro-2,4-dinitrobenzene in HEK 293 cells activated ASK1 leading to apoptosis (36). This provides a direct link between TrxR activity and its negative regulation of apoptosis. In addition, Trx 1 activity is involved in activating transcription 
factors involved in cell proliferation (27), such as nuclear factor- $\kappa \mathrm{B}(20)$ and activator protein 1 (19). We have definitively shown that acetylation increases the intrinsic activity of TrxR1 (Fig. 3A, B), which leads to an increased rate of Trx 1 reduction, thus increasing the activity of the Trx system in reduction of cellular targets, such as insulin (Fig. 3C). Together, these observations suggest that acetylation signaling on TrxR1 may be involved in inhibiting apoptosis and regulating cell viability by increasing the overall activity of the Trx system.

\section{Codon recoding and codon reassignment mechanisms are mutually orthogonal}

Efficient protein production with more than 20 amino acids is a major challenge in the area of genetic code expansion. Protein production at $1.5 \mathrm{mg} / \mathrm{L}$ culture with two different ncAAs in the cell was recently demonstrated by reassigning a UAG codon and a quadruplet codon (AGUA) in the same gene (48). This experiment relied on coexpression of a mutant orthogonal ribosome alongside the endogenous ribosome. Translation products without one or both of the two ncAAs were also observed (48), and it is unclear why this mutant ribosome would be immune to frame-shifting at the site of the four-base codon, which is well documented (13, 32).

In an independent experiment, a GFP reporter containing two different ncAAs was produced at $1-10 \mathrm{mg} / \mathrm{L}$ culture by reassigning both UAG and UAA stop codons (47). The corresponding "wild-type" GFP variant was produced at $56 \mathrm{mg} / \mathrm{L}$ culture (22). These data suggest that GFP with 22 different amino acids was produced at 6- to 50-fold lower levels compared with a GFP containing only the 20 natural amino acids. In contrast, here we established protein synthesis with 22 different amino acids in a recombinant human protein for the first time at $>2 \mathrm{mg} / \mathrm{L}$ culture. Our data indicate we achieved equal efficiency to standard protein production with 20 amino acids.

A key bottleneck in genetic code expansion is a limited availability of "reassignable" codons (31). Traditional genetic code expansion systems alter the meaning of the UAG codon at each instance of that codon in the entire transcriptome $(1,18)$. The $\mathrm{Sec}$ insertion machinery recodes the UGA codon only at genetic loci that are specified by a downstream selenocysteine insertion sequence (SecIS) element (17) (Fig. 1). This means that UGA normally stops protein synthesis, but at specific sites determined by the position of SecIS, the Sec machinery is recruited to change the meaning of UGA from stop to Sec. Sec is not hardwired to $\operatorname{UGA}(3,29)$, and we have previously shown that by simply mutating the tRNA ${ }^{\mathrm{Sec}}$ anticodon, each stop codon and 15 sense codons can be recoded with high fidelity to Sec (3). A recent study showed that recoding UAG to Sec using an SectRNA $^{\text {Sec }}$ with the corresponding UAG-decoding anticodon results in increased UAG translation with $\mathrm{Sec}$ in an RF1deficient $E$. coli strain (5). We have shown here (Table 1) and previously (14) that despite enhanced UAG read-through per cell in the same RF1-deficient E. coli strain (Supplementary Fig. S2), we are able to produce ncAA-containing proteins more efficiently in BL21 as evidenced by 5- to 100-fold higher protein yields per liter $E$. coli culture. This is likely due to the decreased fitness of the RF1-deficient $E$. coli strain, resulting in slower growth (24), and less overall protein production. Together, these data suggest that with an efficient genetic code expansion system, RF1 competition (and translational stopping at UAG) is offset by higher cell densities and overall more efficient protein production in BL21 compared to RF1-deficient E. coli.

Because the Sec system shows surprising efficiency at stop codon (5) and sense codon recoding (3), we are currently engineering this system to incorporate other ncAAs (41). The data here are vital to this engineering effort as they demonstrate that the Sec codon recoding machinery is compatible with, and orthogonal to, traditional genetic code expansion systems based on UAG codon reassignment. In addition, because our system for protein synthesis with 22 amino acids uses normal three-base codons and the native ribosome, it is highly efficient and will be portable to other host expression systems, including mammalian cells $(11,44)$ with minimal intervention.

\section{Materials and Methods}

\section{Bacterial strains and plasmids}

Site-specific insertion of acK into proteins relies on translational read-through of the stop codon UAG (Fig. 1). In an attempt to enhance UAG translation with acK, we expressed TrxR1 variants in an E. coli RF1 deletion strain and in $E$. coli BL21 (DE3) (C2527H; New England Biolabs, Ipswich, MA). We used an E. coli $\triangle \mathrm{RF} 1$ strain [C321. $\Delta$ A.exp, from G. Church (24) via Addgene strain \#49018] that also has all genomic TAG codons mutated to TAA (24). pET-pylT-GFP, containing sfGFP with an in frame UAG codon at position 2 , and pylT as described previously (16), was used for accessing acK incorporation in E. coli $\triangle \mathrm{RF} 1$ (Supplementary Fig. S2).

Site-specific insertion of Sec relies on the translational read-through and site-specific recoding of the stop codon UGA (Fig. 1). E. coli's native Sec insertion machinery was used to site specifically insert Sec as previously (3). E. coli naturally produces Sec-tRNA ${ }_{\text {UCA }}^{\mathrm{Sec}}$ that binds to a specialized elongation factor (SelB), which in turn recognizes an RNA-hairpin loop (SecIS) downstream of the recoded UGA codon (Fig. 1). Human TrxR1 was recombinantly expressed in $E$. coli by placing an $E$. coli SecIS sequence (derived from the $E$. coli fdhF gene) in the $3^{\prime}$ untranslated region ( $3^{\prime}$ UTR) of the TrxR1 expression construct, as previously (3).

To develop a system capable of cotranslational incorporation of both $\mathrm{Sec}$ and $\mathrm{acK}$ in the same polypeptide, human TrxR1 (isoform 4), including the $3^{\prime} f d h F$ SecIS and an in-frame UGA codon (Sec550), was PCR amplified from pRSF-TrxR1-SerS (3) with primers (TRXF-NdeI 5'-CATATGTCCTGCGAAGACGGTCGTGCGC-3', TRXRSacI 5'-GAGCTCTCGGCCGCATAGGCTAACGATTG-3'). The PCR product was digested with $N d e \mathrm{I} / \mathrm{SacI}$ (NEB) and ligated to pET-pylT (16) digested with $N d e \mathrm{I} / \mathrm{Sac}$ I to give $\mathrm{pET}$ pylT-TrxR1 (WT). Quickchange PCR, as described previously (9), was conducted on pET-pylT-TrxR1 (WT) to introduce UAG codons in the TrxR1 expression construct at positions 141, 200, or 307 (residue numbers are based on isoform four numbering). pKTS-acKRS1 (45) containing an engineered $N_{\varepsilon}$-acetyl-lysine tRNA synthetase (16), or pTech-acKRS-tRNA ${ }^{\text {Pyl-opt }}$ containing acKRS and tRNA ${ }^{\text {Pyl-opt }}(12)$, was also required for site-specific 
acK incorporation. The tRNA ${ }^{\text {Pyl-opt }}$ mutant (12) was shown to increase acK incorporation 3-fold relative to the earlier established systems $(30,45)$. pRSF-TrxR1-SerS (3) containing UAC at codon 550 was used for producing inactive TrxR1 Sec550Tyr.

\section{TrxR1 production and purification}

The human TrxR1 variants were overexpressed from the plasmids pET-pylT-TrxR1 in E. coli $\Delta \mathrm{RF} 1$ (24) or E. coli BL21 DE3 that had been cotransformed with pKTS-acKRS1 (45) or pTech-acKRS-tRNA ${ }^{\text {Pyl-opt }}$ (12). Starting from a single colony after transformation on selective agar plates, cells were grown at $37^{\circ} \mathrm{C}$ overnight in a $25 \mathrm{~mL}$ preculture containing lysogeny broth (LB) selective medium (ampicillin $100 \mu \mathrm{g} / \mathrm{mL}$, kanamycin $25 \mu \mathrm{g} / \mathrm{mL}$ for pKTS-acKRS1; or ampicillin $100 \mu \mathrm{g} / \mathrm{mL}$, chloramphenicol $34 \mu \mathrm{g} / \mathrm{mL}$ for pTech-acKRStRNA $\left.{ }^{\text {Pyl-opt }}\right)$. Cells were grown at $37^{\circ} \mathrm{C}$ in $1 \mathrm{~L} \mathrm{LB}$ selective medium (ampicillin $100 \mu \mathrm{g} / \mathrm{mL}$, kanamycin $25 \mu \mathrm{g} / \mathrm{mL}$ for pKTS-acKRS1; or ampicillin $100 \mu \mathrm{g} / \mathrm{mL}$, chloramphenicol $34 \mu \mathrm{g} / \mathrm{mL}$ for pTech-acKRS-tRNA ${ }^{\text {Pyl-opt }}$ ) supplemented with $10 \mu M$ sodium selenite (214485; Sigma) and $2.5 \mathrm{mM} N_{\varepsilon^{-}}$ acetyl-lysine (A2010; Sigma) following inoculation with a $25 \mathrm{~mL}$ preculture. An additional $1.5 \mathrm{~m} M$ acK was added at $\mathrm{OD}_{600}=1.0$, for a total of $4 \mathrm{~m} M N_{\varepsilon}$-acetyl-lysine. Because optimal selenoprotein expression requires late induction (3), at $\mathrm{OD}_{600}=1.2$, the temperature was shifted to $20^{\circ} \mathrm{C}$ and protein expression was then induced at $\mathrm{OD}_{600}=1.5$ with $100 \mu M$ or $1 \mathrm{~m} M$ isopropyl $\beta$-D-1-thiogalactopyranoside (I6758; Sigma) and continued for $18 \mathrm{~h}$ shaking at $20^{\circ} \mathrm{C}$.

After the cells were harvested by centrifugation, the cell pellet was resuspended in $30 \mathrm{~mL}$ phosphate buffer $(100 \mathrm{mM}$ potassium phosphate, $\mathrm{pH} 7.2,10 \%$ glycerol). The cells were supplemented with lysozyme $(0.05 \mathrm{mg} / \mathrm{mL}$, LDB0308; Biobasic) and subsequently disrupted by sonication (Q125; QSonica). The centrifuged lysate $\left(6250 \mathrm{~g}, 1 \mathrm{~h}, 4^{\circ} \mathrm{C}\right)$ was purified by affinity chromatography using $1 \mathrm{~mL} \mathrm{Ni-NTA}$ resin (30230; Qiagen) in a gravity flow column equilibrated with $25 \mathrm{~mL}$ phosphate buffer. After washing with $50 \mathrm{~mL}$ phosphate buffer supplemented with $45 \mathrm{mM}$ imidazole, the proteins were eluted with $5 \times 1 \mathrm{~mL}$ phosphate buffer $(230 \mathrm{mM}$ imidazole). Protein concentration was assessed by the Bradford protein assay (\#5000006; Bio-Rad) at $595 \mathrm{~nm}$ according to the manufacturer's instructions.

Following affinity chromatography, the TrxR1 variants were further purified by size-exclusion chromatography. TrxR1 variants were purified in an AKTA Pure L1 fast protein liquid chromatography (FPLC) system (29018225; GE Healthcare) using a Superdex ${ }^{\mathrm{TM}} 200$ Increase 10/300 GL column (28990944; GE Healthcare) pre-equilibrated in $20 \mathrm{~m} M$ sodium phosphate, $150 \mathrm{~m} M$ sodium chloride, $\mathrm{pH} 7.5$, with a flow rate of $0.3 \mathrm{~mL} / \mathrm{min}$. Elutions were collected in $0.5 \mathrm{~mL}$ fractions.

\section{In vitro TrxR1 activity assay: DTNB}

Enzymatic activity of purified TrxR1 variants was assessed colorimetrically by monitoring NADPH (N7505; Sigma)dependent reduction of Ellman's reagent (DTNB, D8130; Sigma). A plate reader (Synergy H1 Hybrid Multi-Mode Reader, 11-120-534; BioTek) autodispenser was used to add DTNB (in phosphate buffer) to each well to start the reactions, which included final concentrations of $5 \mathrm{~m} M$ DTNB, $300 \mu M$ $\mathrm{NADPH}$, and $50 \mathrm{n} M$ (Fig. 3A) or $100 \mathrm{n} M$ (Fig. 7B) TrxR1 in a final volume of $100 \mu \mathrm{L}$ per well. This reaction was monitored at $412 \mathrm{~nm}$ every minute for $50 \mathrm{~min}$. Reactions were performed in triplicate. For all activity assays, error bars display one standard deviation based on at least triplicate experiments. A control lacking the TrxR1 enzyme was conducted in triplicate and has been subtracted from all enzyme assays.

\section{In vitro TrxR1 activity assay: 9, 10-phenathrenequinone}

Enzymatic activity of purified TrxR1 variants was assessed colorimetrically by following oxidation of NADPH resulting from TrxR1-mediated and Sec-dependent reduction of 9,10phenathrenequinone (275034; Aldrich). NADPH consumption was monitored by incubating $100 \mathrm{n} M$ TrxR1 with $300 \mu M$ NADPH and $50 \mu M$ 9,10-phenanthrenequinone in phosphate buffer $(100 \mathrm{~m} M$ potassium phosphate, $\mathrm{pH}$ 7.0, $1 \mathrm{~m} M$ ethylenediaminetetraacetic acid [EDTA, E9884; Sigma]). TrxR1 and NADPH in phosphate buffer with EDTA were added to the wells of a 96-well plate. A 96-well plate reader autodispenser was used to add 9,10-phenanthrenequinone in phosphate buffer to each well to start the reaction with a final volume of $100 \mu \mathrm{L}$. The assay mixture was monitored at $340 \mathrm{~nm}$ every minute for $2 \mathrm{~h}$, in a 96-well plate reader. A no enzyme control was conducted in triplicate and subtracted from the TrxR1 reactions. Reactions were performed in triplicate.

\section{HDAC3 assays}

WT and acTrxR1 variants $(0.75 \mu M)$ were incubated with $4 \mu M$ HDAC3 (SRP2072; Sigma) for $2 \mathrm{~h}$ at $37^{\circ} \mathrm{C}$. Following this incubation, the enzymatic activity of TrxR1 variants incubated with or without HDAC3 was assessed colorimetrically by the in vitro DTNB activity assay described above, with a final TrxR1 concentration of $3.75 \mathrm{n} M$. Reactions were performed in triplicate, and error bars represent one standard deviation.

\section{Insulin linked TrxR1 activity assays}

The enzymatic activity of TrxR1 on recombinant human Trx1 (T8690; Sigma) was assessed by following the oxidation of NAPDH $(340 \mathrm{~nm})$ resulting from TrxR1-mediated reduction of Trx1. In this insulin linked assay, Trx 1 then reduces recombinant human insulin (91077C; Sigma) before being reduced by TrxR1 again. TrxR1 (200 nM) was incubated with $50 \mu M \mathrm{NADPH}, 1 \mathrm{~m} M$ EDTA, $80 \mu M$ insulin, and $6 \mu M \operatorname{Trx} 1$ in phosphate buffer in a volume of $200 \mu \mathrm{L}$ in wells of a 96well plate. The reaction was started by the addition of Trx 1 and insulin. The reactions were monitored at $340 \mathrm{~nm}$ every minute for $10 \mathrm{~min}$ using a plate reader. Reactions were performed in triplicate. Error bars represent one standard deviation. A no TrxR1 control (performed in triplicate) has been subtracted from all reactions.

\section{Statistical analysis}

All errors bars represent one standard deviation. All $p$ values were derived from an analysis of variance one-way statistical analysis of data produced in triplicate. Initial velocity calculations in Table 1 are calculated from the linear phase of the activity curves (Fig. 3).

\section{Mass spectrometry}

Mass spectrometric analyses of purified TrxR1 variants were performed at the MALDI mass spectrometry facility 
(The University of Western Ontario) for MALDI-MS and the UWO Biological Mass Spectrometry Laboratory (The University of Western Ontario) or the W.M. Keck Biotechnology Resource Laboratory (Yale University) for LCMS/MS. TrxR1 variants were run on a $15 \%$ sodium dodecyl sulfate (SDS) gel, Coomassie stained, and prepared for MALDI-MS or LC-MS/MS by digestion with trypsin protease. A MassPREP automated digester station (PerkinElmer) was used to digest the TrxR1 variants with $5 \mathrm{ng} / \mu \mathrm{L}$ trypsin (Promega). Coomassie-stained gel pieces were destained with $50 \mathrm{~m} M$ ammonium bicarbonate and $50 \%$ acetonitrile. TrxR1 variants were then reduced with $10 \mathrm{~m} M$ dithiothreitol, alkylated with $55 \mathrm{~m} M$ acrylamide, and digested with trypsin. LC-MS/MS was performed using a Q-Tof Micro mass spectrometer (Waters) equipped with a $\mathrm{Z}$-spray source and run in positive ion mode $(+0.1 \%$ formic acid) or using Thermo Scientific LTQ-Orbitrap XL mass spectrometer. MALDI-MS was performed using an AB Sciex 5800 TOF/TOF system, MALDI TOF-TOF (Framingham, MA) equipped with a $349 \mathrm{~nm}$ Nd:YLF OptiBeam On-Axis laser using a laser pulse rate of $400 \mathrm{~Hz}$ and reflectron positive mode. The MALDI matrix used was $\alpha$ cyano-4-hydroxycinnamic acid, prepared as $5 \mathrm{mg} / \mathrm{mL}$ in $6 \mathrm{~m} M$ ammonium phosphate monobasic, $50 \%$ acetonitrile, $0.1 \%$ trifluoroacetic acid, and was mixed with the samples at a $1: 1$ ratio $(\mathrm{v} / \mathrm{v})$. ICP-MS was performed to quantify the amount of selenium per amount of protein for TrxR1 variants at Biotron Analytical Services (The University of Western Ontario).

\section{Western blot analysis of TrxR1 expression}

Purified TrxR1 proteins were resuspended in $1 \times$ SDS loading buffer (250 mM Tris/HCl pH 6.8, 40\% glycerol [v/v], 10\% SDS [w/v], $0.05 \%$ bromophenol blue [w/v], 5\% 2-mercaptoethanol) and loaded in $10 \%$ SDS-polyacrylamide gel electrophoresis. The blot was carried out with a TransBlot Turbo Transfer System (BioRad). Anti-His antibodies (from Mouse, H1029; Sigma) and mouse immunoglobulin $\mathrm{G}$ horseradish peroxidase linked whole antibody (from sheep, GENA931; GE Healthcare) were used. Chemiluminescent signal detection was performed on a ChemiDoc MP system (BioRad).

\section{Size exclusion chromatography}

TrxR1 variants and proteins from a high-molecular-weight calibration kit (28403842; GE Healthcare) were individually separated in an AKTA Pure L1 FPLC system using a Superdex 200 Increase 10/300 GL column pre-equilibrated in $20 \mathrm{~m} M$ sodium phosphate, $150 \mathrm{~m} M$ sodium chloride, $\mathrm{pH}$ 7.5. Elutions were collected in $0.5 \mathrm{~mL}$ fractions. The highmolecular-weight calibration kit used the following proteins: ovalbumin ( $43 \mathrm{kDa}, 3 \mathrm{mg} / \mathrm{mL})$, conalbumin $(75 \mathrm{kDa}, 3 \mathrm{mg} /$ $\mathrm{mL})$, aldolase $(158 \mathrm{kDa}, 3 \mathrm{mg} / \mathrm{mL})$, ferritin $(440 \mathrm{kDa}, 1 \mathrm{mg} /$ $\mathrm{mL})$, thyroglobulin $(669 \mathrm{kDa}, 3 \mathrm{mg} / \mathrm{mL})$, and blue dextran (2000 kDa, $1 \mathrm{mg} / \mathrm{mL})$.

\section{Acknowledgments}

This work is supported by grants to P.O. from the Natural Sciences and Engineering Research Council of Canada (RGPIN 04282-2014), Canada Research Chairs (950229917), Canada Foundation for Innovation (229917), On- tario Research Fund (229917), Canadian Cancer Society Research Institute (704324), and Western University. We are thankful to Elias Arnér, Ilka Heinemann, Shawn Li, Lars Konermann, Noah Reynolds, and Dieter Söll for discussions.

\section{Author Disclosure Statement}

No competing financial interests exist.

\section{References}

1. Aerni HR, Shifman MA, Rogulina S, O'Donoghue P, and Rinehart J. Revealing the amino acid composition of proteins within an expanded genetic code. Nucleic Acids Res 43: e8, 2015.

2. Banerjee Mustafi S, Grose JH, Zhang H, Pratt GW, Sadoshima J, Christians ES, and Benjamin IJ. Aggregateprone R120GCRYAB triggers multifaceted modifications of the thioredoxin system. Antioxid Redox Signal 20: 28912906, 2014.

3. Bröcker MJ, Ho JM, Church GM, Söll D, and O'Donoghue P. Recoding the genetic code with selenocysteine. Angew Chem Int Ed Engl 53: 319-323, 2014.

4. Cenas N, Nivinskas H, Anusevicius Z, Sarlauskas J, Lederer $\mathrm{F}$, and Arner ES. Interactions of quinones with thioredoxin reductase: a challenge to the antioxidant role of the mammalian selenoprotein. J Biol Chem 279: 25832592, 2004.

5. Cheng Q and Arner ES. Selenocysteine insertion at a predefined UAG codon in a release factor 1 (RF1) depleted Escherichia coli host strain bypasses species barriers in recombinant selenoprotein translation. J Biol Chem 292: 5476-5487, 2017.

6. Cheng Q, Sandalova T, Lindqvist Y, and Arner ES. Crystal structure and catalysis of the selenoprotein thioredoxin reductase 1. J Biol Chem 284: 3998-4008, 2009.

7. Choudhary C, Kumar C, Gnad F, Nielsen ML, Rehman M, Walther TC, Olsen JV, and Mann M. Lysine acetylation targets protein complexes and co-regulates major cellular functions. Science 325: 834-840, 2009.

8. Dong C, Zhang L, Sun R, Liu J, Yin H, Li X, Zheng X, and Zeng $\mathrm{H}$. Role of thioredoxin reductase 1 in dysplastic transformation of human breast epithelial cells triggered by chronic oxidative stress. Sci Rep 6: 36860, 2016.

9. Edelheit O, Hanukoglu A, and Hanukoglu I. Simple and efficient site-directed mutagenesis using two singleprimer reactions in parallel to generate mutants for protein structure-function studies. BMC Biotechnol 9: 61, 2009.

10. Eichler J and Maupin-Furlow J. Post-translation modification in Archaea: lessons from Haloferax volcanii and other haloarchaea. FEMS Microbiol Rev 37: 583-606, 2013.

11. Elsasser SJ, Ernst RJ, Walker OS, and Chin JW. Genetic code expansion in stable cell lines enables encoded chromatin modification. Nat Methods 13: 158-164, 2016.

12. Fan C, Xiong H, Reynolds NM, and Söll D. Rationally evolving tRNA ${ }^{\text {Pyl }}$ for efficient incorporation of noncanonical amino acids. Nucleic Acids Res 43: e156, 2015.

13. Farabaugh PJ. Translational frameshifting: implications for the mechanism of translational frame maintenance. Prog Nucleic Acid Res Mol Biol 64: 131-170, 2000.

14. George S, Aguirre JD, Spratt DE, Bi Y, Jeffery M, Shaw GS, and O'Donoghue P. Generation of phospho-ubiquitin 
variants by orthogonal translation reveals codon skipping. FEBS Lett 590: 1530-1542, 2016.

15. Gorrini C, Harris IS, and Mak TW. Modulation of oxidative stress as an anticancer strategy. Nat Rev Drug Discov 12: 931-947, 2013.

16. Guo LT, Wang YS, Nakamura A, Eiler D, Kavran JM, Wong M, Kiessling LL, Steitz TA, O'Donoghue P, and Söll D. Polyspecific pyrrolysyl-tRNA synthetases from directed evolution. Proc Natl Acad Sci U S A 111: 16724-16729, 2014.

17. Heider J, Baron C, and Böck A. Coding from a distance: dissection of the mRNA determinants required for the incorporation of selenocysteine into protein. EMBO $J 11$ : 3759-3766, 1992.

18. Heinemann IU, Rovner AJ, Aerni HR, Rogulina S, Cheng L, Olds W, Fischer JT, Söll D, Isaacs FJ, and Rinehart J. Enhanced phosphoserine insertion during Escherichia coli protein synthesis via partial UAG codon reassignment and release factor 1 deletion. FEBS Lett 586: 3716-3722, 2012.

19. Hirota K, Matsui M, Iwata S, Nishiyama A, Mori K, and Yodoi J. AP-1 transcriptional activity is regulated by a direct association between thioredoxin and Ref-1. Proc Natl Acad Sci U S A 94: 3633-3638, 1997.

20. Hirota K, Murata M, Sachi Y, Nakamura H, Takeuchi J, Mori K, and Yodoi J. Distinct roles of thioredoxin in the cytoplasm and in the nucleus. A two-step mechanism of redox regulation of transcription factor NF-kappaB. J Biol Chem 274: 27891-27897, 1999.

21. Hornbeck PV, Zhang B, Murray B, Kornhauser JM, Latham V, and Skrzypek E. PhosphoSitePlus, 2014: mutations, PTMs and recalibrations. Nucleic Acids Res 43: D512-D520, 2015.

22. Huang Y, Russell WK, Wan W, Pai PJ, Russell DH, and Liu W. A convenient method for genetic incorporation of multiple noncanonical amino acids into one protein in Escherichia coli. Mol Biosyst 6: 683-686, 2010.

23. Kawaguchi Y, Ito A, Appella E, and Yao TP. Charge modification at multiple C-terminal lysine residues regulates p53 oligomerization and its nucleus-cytoplasm trafficking. J Biol Chem 281: 1394-1400, 2006.

24. Lajoie MJ, Rovner AJ, Goodman DB, Aerni HR, Haimovich AD, Kuznetsov G, Mercer JA, Wang HH, Carr PA, Mosberg JA, Rohland N, Schultz PG, Jacobson JM, Rinehart J, Church GM, and Isaacs FJ. Genomically recoded organisms expand biological functions. Science 342: 357360, 2013.

25. Lamoke F, Ripandelli G, Webster S, Montemari A, Maraschi A, Martin P, Marcus DM, Liou GI, and Bartoli M. Loss of thioredoxin function in retinas of mice overexpressing amyloid beta. Free Radic Biol Med 53: 577588, 2012.

26. Lamoke F, Stampley C, Maraschi A, Fan F, Montemari A, Marcus DM, Martin PM, and Bartoli M. Epigenetic regulation of endogenous antioxidants in the diabetic retina. Invest Ophthalmol Vis Sci 52: 4448, 2011.

27. Lu J and Holmgren A. Thioredoxin system in cell death progression. Antioxid Redox Signal 17: 1738-1747, 2012.

28. Luthman $M$ and Holmgren $A$. Rat liver thioredoxin and thioredoxin reductase: purification and characterization. Biochemistry 21: 6628-6633, 1982.

29. Mukai T, Englert M, Tripp HJ, Miller C, Ivanova NN, Rubin EM, Kyrpides NC, and Söll D. Facile recoding of selenocysteine in nature. Angew Chem Int Ed Engl 55: 5337-5341, 2016.
30. Neumann H, Peak-Chew SY, and Chin JW. Genetically encoding N(epsilon)-acetyllysine in recombinant proteins. Nat Chem Biol 4: 232-234, 2008.

31. O’Donoghue P, Ling J, Wang YS, and Söll D. Upgrading protein synthesis for synthetic biology. Nat Chem Biol 9: 594-598, 2013.

32. O’Donoghue P, Prat L, Heinemann IU, Ling J, Odoi K, Liu WR, and Söll D. Near-cognate suppression of amber, opal and quadruplet codons competes with aminoacyl-tRNA ${ }^{\text {Pyl }}$ for genetic code expansion. FEBS Lett 586: 3931-3937, 2012.

33. Parmigiani RB, Xu WS, Venta-Perez G, ErdjumentBromage H, Yaneva M, Tempst P, and Marks PA. HDAC6 is a specific deacetylase of peroxiredoxins and is involved in redox regulation. Proc Natl Acad Sci U S A 105: 96339638, 2008.

34. Rodman SN, Spence JM, Ronnfeldt TJ, Zhu Y, Solst SR, O'Neill RA, Allen BG, Guan X, Spitz DR, and Fath MA. Enhancement of radiation response in breast cancer stem cells by inhibition of thioredoxin- and glutathionedependent metabolism. Radiat Res 186: 385-395, 2016.

35. Roh JL, Jang H, Kim EH, and Shin D. Targeting of the glutathione, thioredoxin, and Nrf2 antioxidant systems in head and neck cancer. Antioxid Redox Signal 27: 106-114, 2017.

36. Saitoh M, Nishitoh H, Fujii M, Takeda K, Tobiume K, Sawada Y, Kawabata M, Miyazono K, and Ichijo H. Mammalian thioredoxin is a direct inhibitor of apoptosis signal-regulating kinase (ASK) 1. EMBO J 17: 2596-2606, 1998.

37. Schieber M and Chandel NS. ROS function in redox signaling and oxidative stress. Curr Biol 24: R453-R462, 2014.

38. Schweizer U and Fradejas-Villar N. Why 21? The significance of selenoproteins for human health revealed by inborn errors of metabolism. FASEB J 30: 3669-3681, 2016.

39. Selenius M, Rundlof AK, Olm E, Fernandes AP, and Bjornstedt M. Selenium and the selenoprotein thioredoxin reductase in the prevention, treatment and diagnostics of cancer. Antioxid Redox Signal 12: 867-880, 2010.

40. Soppa J. Protein acetylation in archaea, bacteria, and eukaryotes. Archaea 2010: [Epub ahead of print]; DOI: 10.1155/2010/820681, 2010.

41. Stafforst T. The selenocysteine incorporation machinery allows the dual use of sense codons: a new strategy for expanding the genetic code? Chembiochem 15: 356-358, 2014.

42. Tamura T and Stadtman TC. A new selenoprotein from human lung adenocarcinoma cells: purification, properties, and thioredoxin reductase activity. Proc Natl Acad Sci US A 93: 1006-1011, 1996.

43. Tse C, Sera T, Wolffe AP, and Hansen JC. Disruption of higher-order folding by core histone acetylation dramatically enhances transcription of nucleosomal arrays by RNA polymerase III. Mol Cell Biol 18: 4629-4638, 1998.

44. Turanov AA, Lobanov AV, Hatfield DL, and Gladyshev VN. UGA codon position-dependent incorporation of selenocysteine into mammalian selenoproteins. Nucleic Acids Res 41: 6952-6959, 2013.

45. Umehara T, Kim J, Lee S, Guo LT, Söll D, and Park HS. Nacetyl lysyl-tRNA synthetases evolved by a CcdB-based selection possess $N$-acetyl lysine specificity in vitro and in vivo. FEBS Lett 586: 729-733, 2012. 
46. Ungerstedt JS, Sowa Y, Xu WS, Shao Y, Dokmanovic M, Perez G, Ngo L, Holmgren A, Jiang X, and Marks PA. Role of thioredoxin in the response of normal and transformed cells to histone deacetylase inhibitors. Proc Natl Acad Sci US A 102: 673-678, 2005.

47. Wan W, Huang Y, Wang Z, Russell WK, Pai PJ, Russell $\mathrm{DH}$, and Liu WR. A facile system for genetic incorporation of two different noncanonical amino acids into one protein in Escherichia coli. Angew Chem Int Ed Engl 49: 32113214, 2010.

48. Wang K, Sachdeva A, Cox DJ, Wilf NM, Lang K, Wallace S, Mehl RA, and Chin JW. Optimized orthogonal translation of unnatural amino acids enables spontaneous protein double-labelling and FRET. Nat Chem 6: 393403, 2014.

49. Wang L, Yang Z, Fu J, Yin H, Xiong K, Tan Q, Jin H, Li J, Wang T, Tang W, Yin J, Cai G, Liu M, Kehr S, Becker $\mathrm{K}$, and Zeng $\mathrm{H}$. Ethaselen: a potent mammalian thioredoxin reductase 1 inhibitor and novel organoselenium anticancer agent. Free Radic Biol Med 52: 898-908, 2012.

50. Weinert BT, Scholz C, Wagner SA, Iesmantavicius V, Su $\mathrm{D}$, Daniel JA, and Choudhary C. Lysine succinylation is a frequently occurring modification in prokaryotes and eukaryotes and extensively overlaps with acetylation. Cell Rep 4: 842-851, 2013.

51. Wolfe AJ. Bacterial protein acetylation: new discoveries unanswered questions. Curr Genet 62: 335-341, 2016.

52. Wu Q, Cheng Z, Zhu J, Xu W, Peng X, Chen C, Li W, Wang F, Cao L, Yi X, Wu Z, Li J, and Fan P. Suberoylanilide hydroxamic acid treatment reveals crosstalks among proteome, ubiquitylome and acetylome in nonsmall cell lung cancer A549 cell line. Sci Rep 5: 9520, 2015.

53. Xia L, Nordman T, Olsson JM, Damdimopoulos A, Bjorkhem-Bergman L, Nalvarte I, Eriksson LC, Arner ES, Spyrou G, and Bjornstedt M. The mammalian cytosolic selenoenzyme thioredoxin reductase reduces ubiquinone. A novel mechanism for defense against oxidative stress. $J$ Biol Chem 278: 2141-2146, 2003.

54. Xu J, Eriksson SE, Cebula M, Sandalova T, Hedstrom E, Pader I, Cheng Q, Myers CR, Antholine WE, Nagy P, Hellman U, Selivanova G, Lindqvist Y, and Arner ES. The conserved Trp114 residue of thioredoxin reductase 1 has a redox sensor-like function triggering oligomerization and crosslinking upon oxidative stress related to cell death. Cell Death Dis 6: e1616, 2015.
Address correspondence to: Dr. Patrick O'Donoghue Department of Biochemistry

Department of Chemistry

The University of Western Ontario 1151 Richmond Street London, ON N6A 5C1

Canada

E-mail: patrick.odonoghue@uwo.ca

Date of first submission to ARS Central, March 24, 2017; date of final revised submission, October 20, 2017; date of acceptance, November 4, 2017.

\begin{tabular}{|c|}
\hline 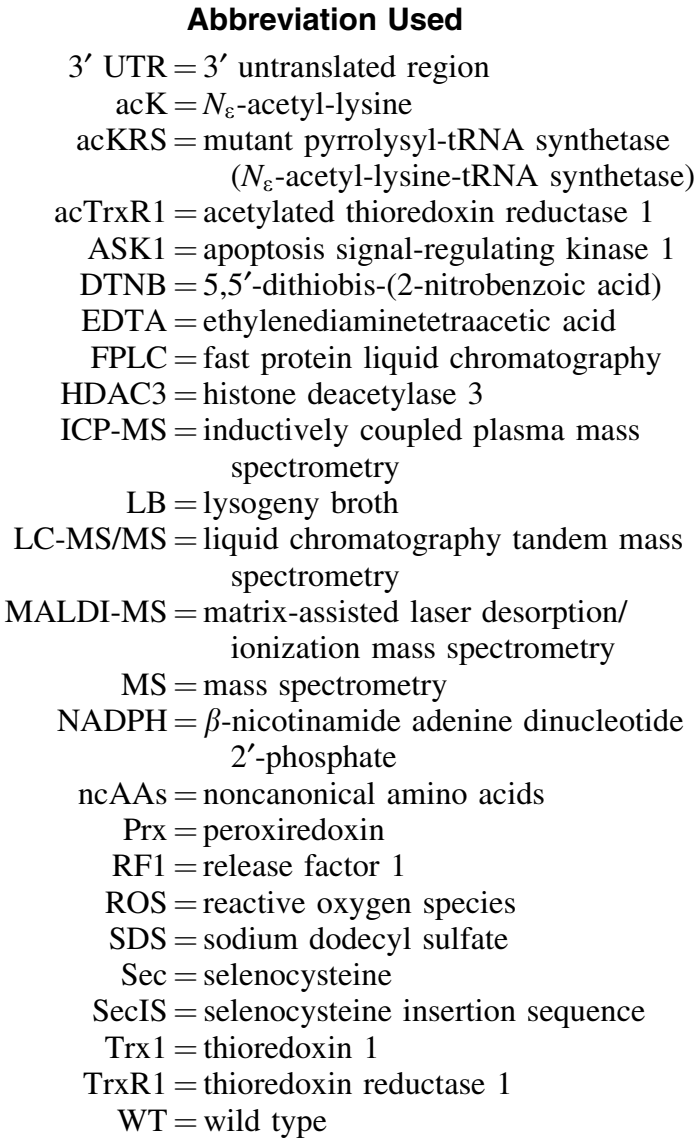 \\
\hline
\end{tabular}

